\title{
Initial hospitalisation for atrial fibrillation in Aboriginal and non-Aboriginal populations in Western Australia
}

Judith M Katzenellenbogen ${ }^{1} \mathrm{PhD}$

Tiew Hwa Katherine Teng ${ }^{2} \mathrm{PhD}$

Derrick Lopez ${ }^{3} \mathrm{PhD}$

Joe Hung ${ }^{4}$ MB BS(Hons), FRACP, FACC

Matthew W Knuiman ${ }^{5} \mathrm{PhD}$

Frank M Sanfilippo ${ }^{6} \mathrm{PhD}$

Michael S T Hobbs ${ }^{7}$ DPhil

Sandra C Thompson ${ }^{8} \mathrm{PhD}$

${ }^{1}$ Research Associate Professor, Western Australian Centre for Rural Health, The University of Western Australia, 35 Stirling Highway, Crawley, Perth, WA 6009, Australia

Tel: +61 893467248 Fax: +61 893461361 Email: Judith.katzenellenbogen@uwa.edu.au

${ }^{2}$ Research Assistant Professor, Western Australian Centre for Rural Health, The University of Western Australia, 35 Stirling Highway, Crawley, Perth, WA 6009, Australia

${ }^{3}$ Research Assistant Professor, Western Australian Centre for Rural Health, The University of Western Australia, 35 Stirling Highway, Crawley, Perth, WA 6009, Australia

${ }^{4}$ Professor and Consultant Cardiologist, Sir Charles Gairdner Hospital, Nedlands and School of Medicine \& Pharmacology, The University of Western Australia, 35 Stirling Highway, Crawley, Perth, WA 6009, Australia

${ }^{5}$ Winthrop Professor, School of Population Health, The University of Western Australia, 35 Stirling Highway, Crawley, Perth, WA 6009, Australia

${ }^{6}$ Research Associate Professor, School of Population Health, The University of Western Australia, 35 Stirling Highway, Crawley, Perth, WA 6009, Australia

${ }^{6}$ Emeritus Professor, School of Population Health, The University of Western Australia, 35 Stirling Highway, Crawley, Perth, WA 6009, Australia

${ }^{7}$ Director and Winthrop Professor, Western Australian Centre for Rural Health, The University of Western Australia, 35 Stirling Highway, Crawley, Perth, WA 6009, Australia 


\begin{abstract}
Objective: The epidemiology of atrial fibrillation (AF) among Aboriginal Australians is poorly described. We compared risk factors, incidence rates and mortality outcomes for firstever hospitalised AF among Aboriginal and non-Aboriginal Western Australians 20-84 years.
\end{abstract}

Methods: This retrospective cohort study used whole-of-state person-based linked hospital and deaths data. Incident hospital AF admissions (previous AF admission-free for 15 years) were identified and subsequent mortality determined. Disease-specific comorbidity histories were ascertained by 10-year look-back. Age-standardised incidence rates were estimated and the adjusted risk of 30-day and 1-year mortality calculated using regression methods.

Results: Aboriginal patients accounted for 923 (2.5\%) of 37,097 incident AF admissions during 2000-2009. Aboriginal patients were younger (mean age 54.8 vs 69.3 years), had lower proportions of primary field AF diagnoses and higher comorbidities than nonAboriginal patients. The Aboriginal and non-Aboriginal age-standardised incidence rates per 100,000 for men 20-54 years were 197 and 55 (ratio=3.6), for women 20-54 years were 122 and 19 (ratio=6.4), for men 55-84 years were 1151 and 888 (ratio=1.3), and for women 55-84 years were 1050 and 571 (ratio=1.8). While 30-day mortality was similar, crude one-year mortality risks in Aboriginal and non-Aboriginal patients were 20.6\% and 16.3\% (adjusted hazard ratio=1.24) and $14.4 \%$ and $9.9 \%$ in 30-day survivors (adjusted hazard ratio=1.58).

Conclusions: The incidence (particularly at young ages) and long-term mortality following hospitalised AF is significantly higher in Aboriginal people. Better control of the antecedent risk factors for AF, improved detection and management of AF itself and prevention of its complications are needed. (246 words) 


\section{Key words}

Atrial fibrillation; incidence; mortality; indigenous; Australia; comorbidities 


\section{What is already known about this subject?}

Despite evidence of significant disparities between Aboriginal and non-Aboriginal people in the incidence and prevalence of antecedents of cardiovascular disease, there have been few publications focusing on atrial fibrillation in Aboriginal Australians or minority Indigenous populations in other industrialised countries.

\section{What does this study add?}

This first population-based comparison of antecedent risk factors and initial hospitalisation rates for AF and outcomes between Aboriginal and non-Aboriginal Australians shows that, despite AF usually being an age-related condition, their impacts are evident at much younger ages among Aboriginal than non-Aboriginal populations. One-year (but not 30-day) mortality following first admission was substantially higher among Aboriginal people.

\section{How might this impact on clinical practice?}

Clinicians should screen for cardiovascular disease and associated risk factors in early adulthood, including a high index of suspicion for early-onset AF in Aboriginal Australians. Systems for discharge and service integration between hospital and primary care need to be enhanced to increase long-term use of medications for preventing AF-related complications, thereby improving survival. 


\section{INTRODUCTION (2.988)}

Atrial fibrillation (AF), the most common serious sustained cardiac dysrhythmia, is reaching epidemic proportions globally because of its increasing incidence and prevalence, and the ageing of the population. ${ }^{1-4}$ Heart failure and stroke are common complications, with AF contributing to $15-20 \%$ of strokes and being independently associated with a $50-90 \%$ increase in mortality risk ${ }^{5}$ and significant physical disability. ${ }^{6}$ A recent assessment of the global burden of AF showed substantial geographical variation ${ }^{3}$, being higher in developed countries. While more research on AF in developing countries has been recommended, ${ }^{3,4}$ data regarding AF among Indigenous populations in developed countries are also sparse, despite documented high rates of predisposing factors. ${ }^{7-10}$

Australia’s Indigenous population (Aboriginal and Torres Strait Islander people, hereafter referred to as Aboriginal) have experienced significant social and health disadvantage since colonisation, manifesting in a life expectancy more than a decade shorter than other Australians. ${ }^{11}$ Aboriginal Australians (3\% of total ${ }^{12}$ ) are geographically, linguistically, culturally and historically diverse, yet across all jurisdictions have a young age structure ${ }^{12}$ and a heavy burden of chronic diseases like diabetes, cardiovascular diseases (CVD), chronic kidney disease (CKD) and chronic obstructive pulmonary disease (COPD). ${ }^{10}$ Although Aboriginal people have access to Australia's universal health insurance scheme, the agestandardised burden of CVD among Aboriginal Australians is 4.6 times greater than that of non- Aboriginal people. ${ }^{10}$ The occurrence of many CVDs associated with AF is substantially higher in Aboriginal Australians, with rate ratios being much higher at younger ages and among women. ${ }^{10}$ Evidence of this has been documented in recent studies of rheumatic heart disease (RHD), ${ }^{13}$ acute myocardial infarction (AMI) ${ }^{14,15}, \mathrm{HF}^{16}$ and stroke ${ }^{17}$, yet AF in 
Aboriginal Australians remains poorly described in the literature. This study aimed to describe differences in the clinical profile and incidence between Aboriginal and nonAboriginal people with first-ever hospitalisations with AF in Western Australia (WA) 20002009. It also aimed to examine differentials in the risk of 30-day and 1-year mortality.

\section{METHODS}

\section{Study Design}

This historical cohort study accrued first-ever AF cases using administrative data. Previous event-free status and presence of comorbidities were ascertained through review of preindex-admission data. Cases were followed up for deaths within 30 days and 1-year of the first AF admission.

\section{Data sources and definitions}

Population-based de-identified linked administrative health data from 1985 to 2010 were extracted from the Hospital Morbidity Data Collection and Mortality databases, two of the primary sources within the WA Data Linkage System. ${ }^{18}$ This comprehensive system applies probabilistic matching of records from core statutory data sets to link health data. The quality of the links has been evaluated in audits and validity studies, with the proportions of invalid (false positives) or missed links (false negatives) both estimated at $0.1 \%$ of matches. ${ }^{18}$

All admissions were identified in which a diagnosis of AF was recorded (ICD-10 I48) for any diagnosis field in the hospitalisation record, in patients aged 20-84 years in the period 20002009. AF subtype (paroxysmal/persistent/permanent) could not be differentiated in the data. Using a fixed 15-year look-back period, the patient data were reviewed to exclude prevalent cases, retaining only first-ever hospital admissions for AF. Case numbers were summed for all study years to allow for the small numbers of Aboriginal cases. 
A 10-year look-back period was used to identify comorbidity histories for first-ever AF patients based on past and current admissions. Separate variables were created for known antecedent and prognostic comorbidities, specifically 10-year histories of ischaemic heart disease (IHD), rheumatic/valvular heart disease, hypertension/hypertensive heart disease, HF, cerebrovascular disease, diabetes, CKD and COPD, as well as smoking and alcohol-related admissions. The Charlson Comorbidity Index (CCI), an instrument used for risk adjustment in outcomes research, provided a summary indicator of comorbidity. $\mathrm{CHA}_{2} \mathrm{DS}_{2}$-VASc scores ${ }^{19}$ assessing stroke risk in non-rheumatic AF patients based on age and comorbidities, were also calculated. Residential address was used as the basis for categorization into five categories of the Accessibility/Remoteness Index of Australia ${ }^{20}$ and for allocation into quartiles of the Socio-economic Index for Areas (SEIFA), ${ }^{21}$ an area-level score of socioeconomic status derived from census variables (e.g. income, education, employment). Admission type (emergency/booked), private health insurance, hospital type, age and sex were based on hospital-recorded data at index admission. To account for under-recording of Aboriginal status in Australian health data, ${ }^{22}$ any individual identified as Aboriginal on 25\% or more of previous hospital admissions was coded as Aboriginal. Survival status was based on date of death from mortality records.

Mid-year estimates of the WA resident population, by age, sex and Aboriginal status for each of the 10 years 2000-2009 were sourced from the Australian Bureau of Statistics. ${ }^{12}$ Denominators for the calculation of incidence rates comprised the sum of the population estimates for each calendar year in the study period. 


\section{Statistical analysis}

Given the substantial difference in age structure between Aboriginal and non-Aboriginal populations $^{12}$, the known early onset of CVD in Aboriginals ${ }^{10,14,16}$, and the marked variation in incidence rate ratios for other CVD over the life $\operatorname{span}^{14-16}$, cases were separated into two broad age groups (20-54 and 55-84 years, 54.8 years being the mean age for Aboriginal patients) for analysis of baseline characteristics, incidence rates and mortality. Baseline characteristics of Aboriginal and non-Aboriginal cases were compared using t-tests and ChiSquare tests to determine significance. Age- and sex-specific incidence rates of first hospitalisation with AF were calculated for both populations using WA census denominators. Age-standardised rates were calculated using the classical method, with the 2006 Australian population as the standard. Aboriginal to non-Aboriginal age-specific rate ratios and their confidence intervals were calculated, with age-standardised rate ratios calculated separately for the two broad age groups.

Multivariable logistic regression was used to compare 30-day mortality (binary outcome) in Aboriginal and non-Aboriginal AF patients, while Kaplan-Meier curves (with Log-rank test) and Cox regression models investigated 1-year (for full cohort as well as in 30-day survivors) mortality in time-to-event analyses. Confounders were progressively adjusted for in the following sequence: age alone; additional demographic variables (sex, social disadvantage, residential location); admission-related variables (calendar period, type of admission [emergency/booked], hospital type/location); and principal vs secondary AF diagnosis. Finally, the CCI and specific disease flags were included to adjust for comorbidity history. The proportional hazards assumption for the Cox regression models of 1 year survival was tested using Schoenfeld's test and found to be significantly violated $(\mathrm{p}=0.01)$ in the whole 
cohort analysis, but not in 30-day survivors $(\mathrm{p}=0.542)$. Therefore we have also provided results restricted to 30 day survivors for the 1-year survival analyses.

Interactions between Aboriginal status and a range of covariates were investigated, with age and sex interactions being significant. The full model was thus run separately for each sex and broad age group to determine whether the overall findings were applicable to substrata. A sensitivity analysis was undertaken to determine the effect of using alternative definitions of Aboriginal status.

Approval for the study was obtained from the WA Human Research Ethics Committee, the University of WA Human Research Ethics Committee and the WA Aboriginal Health Ethics Committee.

\section{RESULTS}

\section{Demographic and admission profile of cases}

Of the 37,097 first-ever hospital AF cases, 21,928 (59.1\%) were men and 923 (2.5\%) were Aboriginal. Aboriginal patients were significantly younger than non-Aboriginal cases (47.8 \% versus $11.4 \%<55$ years, $\mathrm{p}<0.001$ ) and more likely than non-Aboriginal cases to be women (Table 1). Place of residence differed significantly between the two groups, with over half of the Aboriginal cases living in very remote areas (compared with 2.7\% nonAboriginals). Aboriginal patients were substantially over-represented in areas of high social disadvantage.

Non-Aboriginal patients were significantly more likely to be admitted to private hospitals and Aboriginal patients to rural hospitals (Table 1: $\mathrm{p}<0.001$ ). Aboriginal patients were more 
likely to be admitted as emergency patients and almost none had private health insurance cover.

\section{Diagnostic and comorbidity profile}

Overall, AF was more likely to be the principal diagnosis in patients aged $<55$ (54\%) than $\geq 55$ years $(29 \%)$ (Table 1$)$. Aboriginal patients were significantly more likely to have AF as a secondary diagnosis, with differences being most marked in the $<55$ year age group (Table 1). Where AF was a secondary diagnosis, other CVDs were the most common principal diagnoses (41\%, data not shown), with Aboriginal patients being more likely than nonAboriginal patients to have a principal diagnosis of heart failure $(\mathrm{p}=0.02)$ or hypertension/hypertensive heart disease in the younger age group $(\mathrm{p}=0.02)$ and $\mathrm{MI}$ in the older age group $(\mathrm{p}=0.03)$.

Ten-year histories of all comorbidities investigated, except stroke in the older group, were significantly more common in Aboriginal cases, with differentials higher in the younger age group, in which crude prevalence was more than four-fold for CKD, alcohol-related admissions, diabetes and rheumatic/valvular heart disease (Table 2). $\mathrm{CHA}_{2} \mathrm{DS}_{2}$-VASc scores were higher in non-rheumatic Aboriginal patients in all broad age groups with differentials greater in younger patients $(\mathrm{p}<0.001)$ as shown by high $\mathrm{CHA}_{2} \mathrm{DS}_{2}$-VASc score of 2 or more being present in 53\% of Aboriginal vs $14 \%$ of non-Aboriginal patients aged $<55$ years (Table $3)$.

\section{Incidence}

Hospitalised AF incidence was higher in Aboriginal than non-Aboriginal patients in all age groups $<65$ years, with rate ratios generally reducing with age and overlapping with unity in 
the 65-74 year and 75-84 year age groups in men and women respectively (Figure 1). In the 20-54 year age group, the Aboriginal age-standardised incidence rates were 197 (95\% CI 174-221) and 122 (95\% CI 104-141) per 100,000 person-years for men and women, respectively. These rates were 3.6 (95\% CI 2.4-5.5) and 6.4 (95\% CI 3.3-12.4) times those for non-Aboriginal men (55 per 100,000: 95\% CI 53-57) and women (19 per 100,000: 95\% CI 18-20), respectively.

In the 55-84 year age group, the Aboriginal age-standardised incidence was 1151 (95\% CI 993-1308) and 1050 (95\% CI 917-1184) per 100,000 person-years for men and women respectively. These rates were 1.3 (95\% CI 0.95-1.8) and 1.8 (95\% CI 1.3-2.6) times those for non-Aboriginal men (888 per 100,000: 95\% CI 875-901) and women (571 per 100,000: 95\% CI 561-581), respectively.

\section{Mortality}

The significant age-adjusted odds ratio (OR) of $1.75(\mathrm{p}<0.001)$ reduced steadily with incremental adjustment, with the full model finding no significant effect $(\mathrm{OR}=0.81 ; \mathrm{p}=0.186)$ of Aboriginal status on 30-day mortality, and diagnosis ranking and comorbidities contributing substantially to the attenuation of effect (Table 4). The fit of the model was excellent (C-statistic for area under the ROC curve=0.816). The fully adjusted effect was non-significant in all gender and age strata. A secondary diagnosis of AF imparted the highest adjusted risk $(\mathrm{OR}=6.53)$ of all covariates, particularly in the $<55$ year group $(\mathrm{OR}=10.58)$

One-year Kaplan-Meier curves for the full cohort (Figure 2) show a cross-over of survival, with Aboriginal patients having marginally (but statistically not significant) better early but 
significantly poorer later survival. For 1-year mortality in 30-day survivors, the independent association of Aboriginal status reduced with incremental adjustment, remaining significant in the full model $(\mathrm{HR}=1.58 ; \mathrm{p}<0.001)$ despite the substantial attenuating influence of comorbidities (Table 4, Figure 2). An increased Aboriginal risk of mortality was evident for men, women and the 55-84 year age group, with only the $<55$ year group's risk not reaching significance. The disparity remained significant in a similar analysis for the full cohort (including 30-day deaths), with a dilution of the effect size $(\mathrm{HR}=1.24 ; \mathrm{p}=0.022)$ and only the female stratum remaining significant (Table 4). Different definitions of Aboriginal status produced similar findings.

\section{DISCUSSION}

This first population-based study of AF in Aboriginal Australians identified substantial differentials between Aboriginal and non-Aboriginal Western Australians in the incidence of first-ever AF hospitalisation and subsequent 1-year mortality. Aboriginal patients were younger, more likely to be women, living in rural and socio-economically disadvantaged areas and attending rural hospitals. Antecedents and other specific comorbidities were more prevalent and weighted comorbidity and $\mathrm{CHA}_{2} \mathrm{DS}_{2}$-VASc scores higher in Aboriginal patients across all ages, although differentials were most striking in younger patients. Agespecific rate ratios, high at young ages, reduced progressively to achieve parity by age 70 years. Thus, compared with non-Aboriginals, age-standardised rates were 3.6-fold higher in Aboriginal men and 6.4-fold higher in Aboriginal women under 55 years. Fully adjusted 30day mortality was similar in Aboriginal and non-Aboriginal patients but 1-year mortality in 30-day survivors was 57\% higher in Aboriginals. 
AF is predominantly an age-related disease, yet imparts a significant burden on the demographically ‘young’ Aboriginal population. Substantial disparities in common AF risk factors including hypertension, obesity, diabetes and alcohol abuse, ${ }^{10,23}$ predisposing cardiovascular diseases $^{13,14,16,17}$ and co-morbidities in Australia are the main drivers of the excess burden. Evidence of this is shown in our study by the higher history of hypertensive and alcohol-related admissions, as well as 2-6-fold higher prevalence of IHD, RHD, HF and diabetes among younger Aboriginal AF cases. Other studies have shown how a broad range of lifestyle factors including high levels of poverty, stress, smoking, substance use, obesity and physical inactivity all contribute to poor vascular health at early ages. ${ }^{23-25}$ Thus, the incidence of MI, HF and diabetes is high in this population, with age-standardised rate ratios being greater than 10 in adults under 39 years and reducing with age. ${ }^{10,14,16}$ These diseases, including AF, are often detected late due to poorer access to or uptake of medical care, particularly in rural areas.

Internationally, studies of AF occurrence and outcomes in indigenous populations are rare. A linked data study using Ontario emergency department and in-hospital admissions estimated the age-adjusted incidence of AF to be 1.7 times higher in the Métis 20 years and older compared with the rest of the Ontario population. ${ }^{8}$ A cross-sectional study of cardiometabolic disease in selected Northern Territory communities found a 3\% crude prevalence of AF in its sample of 436 ( $\geq 18$ years), with no non-Indigenous comparator. ${ }^{24}$ Indigenous AF patients in a single-institution South Australian study had a similar age distribution and high IHD comorbidity to those in our study. ${ }^{26}$ In a cross-sectional study linking survey and administrative male veterans data, Native Americans were found to have an age-adjusted AF prevalence of 5.4 per 100,000 compared with 5.7 and 5.2 among Whites and Pacific Islanders respectively, with Black prevalence being significantly lower. ${ }^{27}$ Unlinked AF hospital 
admissions rates in Waikato, New Zealand were 1.95 and 1.45 times higher among Maori than non-Maori in 45-64 and 65 years and over age groups, respectively. ${ }^{28}$ These studies suggest that AF incidence and prevalence rates may be higher in most indigenous compared with general populations in developed countries (except possibly USA); however differentials appear greater in Australia. Differences in epidemiological findings are likely to be influenced by study design, including the way age is controlled for in the analyses.

Among Aboriginal people hospitalised with AF, particularly at younger ages, the dysrhythmia is more likely than among non-Aboriginal people to be an emergency admission and a secondary diagnosis to other principal diseases, with CVD being the most common. This may reflect disparities between the two ethnic groups in the detection of AF in primary health care and/or in thresholds for admission especially if AF is the principal clinical presentation. The high prevalence of other chronic diseases highlights the clinical and logistical complexity that besets hospitalisation of Aboriginal patients with AF. This requires responses being built into the patient journey at the organisational or system level. ${ }^{25}$ The difference in AF hospitalised as a principal diagnosis also suggests there may be ascertainment bias in incidence estimates based on hospitalisations alone, resulting in underestimate of Aboriginal AF rates and therefore of the disparity.

The higher 1-year mortality but similar 30-day mortality in Aboriginal cases suggests higher underlying disease severity, poorer post-discharge management or both. Long-term underuse of anticoagulants and treatment for complications associated with AF resulting from inferior access to follow-up medical care and adherence with recommended treatments are also likely to play a role. Many of the risk factors associated with increased mortality (e.g. lack of private health insurance; presence of comorbidities) are more common in Aboriginals so that actual differentials in mortality may be higher. The comparatively higher $\mathrm{CHA}_{2} \mathrm{DS}_{2}$-VASc 
scores in non-rheumatic Aboriginal patients across all age groups reflect their higher risk of stroke and mortality, with AF likely being a marker of general vascular risk. ${ }^{29}$ Conversely, the poorer access of Aboriginal people to ambulatory care skews hospitalized AF in Aboriginal people to higher severity, possibly inflating mortality differentials. Either way, the evidence suggests the need for more intensified out-of-hospital management of AF in Aboriginal patients through access to specialist care and specialist support of primary care professionals, augmented by appropriate education. Access and adherence to evidence-based medications are essential for improving outcomes, yet cultural, socio-economic and logistical barriers remain. ${ }^{25}$ Appropriate care that takes these barriers into account is central to enhancing uptake of ambulatory services. ${ }^{25}$

The strengths of this study include being population-based; state-wide hospitalised case ascertainment with a long clearance period; a comprehensive, high quality linkage procedure $^{18}$ and an evidence-based approach to improving Indigenous identification in the system. However, the ICD coding of AF has not been validated except elsewhere ${ }^{30}$, and therapeutic information (including anti-coagulation) was not available in these hospital administrative data. The study is also likely to under-estimate the true community-based incidence in both populations because non-admitted patients were not captured. It is unknown whether disparities in all-of-community incidence would be greater than found here, although hospital presentation of AF is likely to be more severe in Aboriginals due to diagnostic/therapeutic delays. These limitations should be considered when interpreting these findings, with future studies addressing these caveats.

\section{CONCLUSION}


The substantial disparities in AF incidence and mortality reported in this paper have public health and clinical importance for Aboriginal Australians due to the significant morbidity and excess mortality associated with AF, including its complex interaction with other diseases. A focus on interventions for Aboriginal Australians targeting primary prevention to reduce common risk factors for AF and conditions contributing to AF (while also addressing social determinants of health) is essential. There is a concurrent need for secondary prevention including early diagnosis and treatment, and ongoing management of circulatory diseases generally and AF specifically to reduce shown disparities in outcomes. As AF is underinvestigated in the Australian Aboriginal population, further research into its epidemiology, clinical manifestations and management is required. 


\section{Author contributions}

JK conceptualised the study, directed the analysis and was main contributor to the write-up. TKT prepared the data for and undertook the multivariable regression analysis, while DL extracted the linked data and assisted with the calculation of rates. MWK, a biostatistician, provided expert statistical advice and interpretation. JH advised on study design, provided clinical input, and reviewed the manuscript. FS, MH and ST assisted with the interpretation of the data and reviewed the manuscript. All authors read and approved the final submission.

\section{Acknowledgements and sources of funding}

This work was supported by the National Health and Medical Research Council of Australia (Grant Numbers 1031057, 1020373 and Early Career Fellowship Number 037429[JK]). The Western Australian Centre for Rural Health received funding from the Australian Department of Health and Ageing. The authors wish to thank the staff at the Western Australian Data Linkage Branch, and the Department of Health Inpatient Data Collections and Registrar General for the provision of data.

\section{Conflict of interest}

There are no conflicts of interest.

\section{Exclusive Licence Statement}

The Corresponding Author has the right to grant on behalf of all authors and does grant on behalf of all authors, an exclusive licence (or non exclusive for government employees) on a worldwide basis to the BMJ Publishing Group Ltd and its Licensees to permit this article (if accepted) to be published in HEART editions and any other BMJPGL products to exploit all subsidiary rights 


\section{LEGENDS}

\section{Table 1:}

Baseline profile of patients with a 'first-ever' hospitalisation for atrial fibrillation, stratified by broad age group ( $<55$ years; 55 years and over) and Aboriginal status: Western Australia 2000 - 2009

\section{Table 2:}

Comparison of comorbidities in patients with a first-ever hospitalisation for atrial fibrillation between 2000 and 2009, stratified by broad age group (20-54 years; 55-84 years) and Aboriginal status

\section{Table 3:}

Distribution of indicative $\mathrm{CHA}_{2} \mathrm{DS}_{2}$-VASc scores in non-rheumatic Aboriginal patients with atrial fibrillation, by age group and Aboriginal status, Western Australia 2000-09

\section{Table 4:}

Aboriginal to non-Aboriginal ratios from multivariate regression models* for 30-day mortality (odds ratios) and 1-year mortality in 30-day survivors (hazard ratios) following first-ever hospitalisation for atrial fibrillation

\section{Figure 1:}

Aboriginal to non-Aboriginal age-specific incident rate ratios for first-ever hospitalised atrial fibrillation, by sex

\section{Figure 2:}

Unadjusted and risk-adjusted 1-year survival for Aboriginal and non-Aboriginal Western Australians after first-ever Atrial Fibrillation admission (full cohort) 
Table 1: Baseline profile of patients with a 'first-ever' hospitalisation for atrial fibrillation, stratified by broad age group ( $<55$ years; 55 years and over) and Aboriginal status: Western Australia 2000 - 2009

\begin{tabular}{|c|c|c|c|c|c|c|}
\hline \multirow[b]{2}{*}{ Description of Characteristics } & \multicolumn{3}{|c|}{$20-54$ years $(n=4,570)$} & \multicolumn{3}{|c|}{$55-84$ years $(n=32,527)$} \\
\hline & Aboriginal & Non-Aboriginal & p-value & Aboriginal & Non-Aboriginal & p-value \\
\hline Cases (n \%, within ethnic group) & $441(47.8)$ & $4,129(11.4)$ & & $482(52.2)$ & $32,045(88.6)$ & \\
\hline Women, n (\% within age group) & $171(38.8)$ & $1,062(25.7)$ & $<0.001$ & $253(52.5)$ & $13,683(42.7)$ & $<0.001$ \\
\hline Mean age, years \pm SD & $43.6 \pm 8.9$ & $46.0 \pm 7.8$ & $<0.001$ & $65.4 \pm 7.5$ & $72.5 \pm 7.9$ & $<0.001$ \\
\hline \multicolumn{7}{|l|}{ Age groups, n (\%, of total) } \\
\hline - 20-39 years & $129(14.0)$ & $918(2.5)$ & $<0.001$ & & & \\
\hline - $\quad 40-54$ years & $312(33.8)$ & $3,211(8.9)$ & & & & \\
\hline - 55-69 years & & & & $346(37.5)$ & $10,913(30.2)$ & $<0.001$ \\
\hline - $\quad 70-84$ years & & & & $136(14.7)$ & $21,132(58.4)$ & \\
\hline Length of stay, days $\pm S D$ & $8.9 \pm 14.4$ & $5.4 \pm 12.6$ & $<0.001$ & $11.0 \pm 15.6$ & $9.8 \pm 16.7$ & 0.056 \\
\hline \multicolumn{7}{|l|}{ Metropolitan/rural residence, n (\%) } \\
\hline Highly accessible/Metropolitan & $78(17.7)$ & $1,924(46.6)$ & $<0.001$ & $77(16.0)$ & $16,524(51.6)$ & $<0.001$ \\
\hline Accessible & $42(9.5)$ & $1,356(32.8)$ & & $61(12.7)$ & $10,507(32.8)$ & \\
\hline Moderately accessible & $63(14.3)$ & $513(12.5)$ & & $74(15.4)$ & $3,762(11.7)$ & \\
\hline Remote & $13(3.0)$ & $95(2.3)$ & & $17(3.5)$ & $530(1.7)$ & \\
\hline Very remote & $245(55.5)$ & $241(5.8)$ & & $253(52.5)$ & $722(2.3)$ & \\
\hline \multicolumn{7}{|l|}{ SEIFA -quartiles, n (\%) } \\
\hline $1^{\text {st }}$ quartile (highest disadvantage) & $292(66.2)$ & $771(18.7)$ & $<0.001$ & 337 (69.9) & $7,120(22.2)$ & $<0.001$ \\
\hline $2^{\text {nd }}$ quartile & $106(24.0)$ & $1,456(35.3)$ & & $103(21.4)$ & $11,571(36.1)$ & \\
\hline $3^{\text {rd }}$ quartile & $35(7.9)$ & $1,001(24.3)$ & & $30(6.2)$ & $7,163(22.2)$ & \\
\hline $4^{\text {th }}$ quartile (lowest disadvantage) & $8(1.8)$ & $893(21.7)$ & & $12(2.5)$ & $6,179(19.2)$ & \\
\hline Missing & & $8(0.2)$ & & & $12(0.3)$ & \\
\hline \multicolumn{7}{|l|}{ Hospital type } \\
\hline Metropolitan tertiary/teaching & $200(45.3)$ & $1,811(43.9)$ & $<0.001$ & $214(44.4)$ & $14,627(45.7)$ & $<0.001$ \\
\hline
\end{tabular}




\begin{tabular}{|c|c|c|c|c|c|c|}
\hline Metropolitan non-teaching & $13(2.9)$ & $229(5.6)$ & & $18(3.7)$ & $2,097(6.5)$ & \\
\hline Rural regional hospital & $99(22.5)$ & $404(9.8)$ & & $109(22.6)$ & $2,225(6.9)$ & \\
\hline Rural district/small hospital & $123(27.9)$ & $371(9.0)$ & & $128(26.6)$ & $1,670(5.2)$ & \\
\hline Private & $6(1.4)$ & $1,313(31.7)$ & & $13(2.7)$ & $11,423(35.4)$ & \\
\hline \multicolumn{7}{|l|}{ Private health insurance, n (\%) } \\
\hline No membership & $437(99.1)$ & $2,506(60.7)$ & $<0.001$ & $471(97.7)$ & $19,755(61.7)$ & $<0.001$ \\
\hline Emergency admission, n (\%) & $379(85.9)$ & $2,805(67.9)$ & $<0.001$ & $408(84.7)$ & $20,688(64.6)$ & $<0.001$ \\
\hline \multicolumn{7}{|l|}{ Principal diagnosis, n (\%) } \\
\hline Atrial fibrillation & $127(28.8)$ & $2,347(56.8)$ & $<0.001$ & $91(18.9)$ & $9,473(29.6)$ & $<0.001$ \\
\hline All ischaemic heart disease & 48 (10.9) & 284 (6.9) & 0.771 & $78(16.2)$ & 4,095 (12.8) & 0.358 \\
\hline Myocardial infarction & $22(5.0)$ & $118(2.9)$ & 0.801 & $43(8.9)$ & $1,794(5.6)$ & 0.028 \\
\hline Heart Failure & $36(8.2)$ & $134(3.2)$ & 0.018 & $37(7.7)$ & $1,619(5.1)$ & 0.083 \\
\hline Hypertension/Hypertensive heart disease & $85(19.3)$ & $375(9.1)$ & 0.017 & $75(15.6)$ & $4,044(12.6)$ & 0.518 \\
\hline Bronchopneumonia & $38(8.6)$ & $51(1.2)$ & $<0.001$ & 38 (7.9) & $1,109(3.5)$ & $<0.001$ \\
\hline Stroke/Cerebrovascular disease & $12(2.7)$ & $70(1.7)$ & 0.928 & $24(5.0)$ & $1,801(5.6)$ & 0.182 \\
\hline Cancer & $10(2.3)$ & $116(2.8)$ & 0.022 & $20(4.1)$ & $2,058(6.4)$ & 0.006 \\
\hline \multicolumn{7}{|l|}{ Mortality } \\
\hline 30-day deaths & $28(6.5)$ & $104(2.5)$ & $<0.001$ & $36(7.5)$ & $2420(7.6))$ & 0.941 \\
\hline Cause of death & & & 0.491 & & & 0.087 \\
\hline Ischaemic Heart Disease & $<5$ & $5(4.8)$ & & 5 (13.9) & $490(20.2)$ & \\
\hline Stroke & 0 & $6(5.8)$ & & $<5$ & $127(5.2)$ & \\
\hline Other cardiovascular disease & $<5$ & $12(11.5)$ & & $<5$ & 334 (13.8) & \\
\hline Other & $24(85.7)$ & $81(77.9)$ & & $29(80.6)$ & $1,469(60.7)$ & \\
\hline Cumulative 1-year deaths (whole cohort) & $59(15.1)$ & $193(5.3)$ & $<0.001$ & $110(25.6)$ & 5,055 (17.7) & $<0.001$ \\
\hline \multicolumn{7}{|l|}{ Cause of death } \\
\hline Ischaemic Heart Disease & 7 (11.9) & $16(8.3)$ & & $18(16.4)$ & 974 (19.3) & \\
\hline Stroke & $<5$ & $8(4.1)$ & & $<5$ & $249(4.9)$ & \\
\hline
\end{tabular}


**SEIFA: Socio-Economic Index for Areas

Continuous variables expressed as mean \pm SD. Categorical variables expressed as proportions, $\mathrm{n}(\%)$.

$\mathrm{p}$-value is for difference between Aboriginal and non-Aboriginal patients

The ethics committee requires that all cell sizes $<5$ be suppressed 
Table 2: Comparison of comorbidities in patients with a first-ever hospitalisation for atrial fibrillation between 2000 and 2009 , stratified by broad age group (20-54 years; 55-84 years ) and Aboriginal status

\begin{tabular}{|c|c|c|c|c|c|c|}
\hline \multirow[t]{2}{*}{ Description } & \multicolumn{3}{|c|}{$20-54$ years $(n=4,570)$} & \multicolumn{3}{|c|}{$55-84$ years $(n=32,527)$} \\
\hline & $\begin{array}{l}\text { Aboriginal } \\
(n=441)\end{array}$ & $\begin{array}{l}\text { Non-Aboriginal } \\
(n=4,129)\end{array}$ & p-value & $\begin{array}{l}\text { Aboriginal } \\
(\mathrm{n}=482)\end{array}$ & $\begin{array}{l}\text { Non-Aboriginal } \\
(n=32,045)\end{array}$ & p-value \\
\hline \multicolumn{7}{|l|}{ 10-year comorbidity history, $\mathrm{n}(\%)$ * } \\
\hline All ischaemic heart disease $\dagger$ & $109(24.7)$ & $373(9.0)$ & 0.001 & $165(34.2)$ & $8,432(26.3)$ & $<0.001$ \\
\hline Rheumatic/valvular heart disease & $79(17.9)$ & $168(4.1)$ & $<0.001$ & $31(6.4)$ & $1,368(4.3)$ & 0.02 \\
\hline Hypertension/hypertensive heart disease & $178(40.4)$ & $448(10.9)$ & $<0.001$ & $278(57.7)$ & $11,570(36.1)$ & $<0.001$ \\
\hline Heart failure & $172(39.0)$ & $496(12.0)$ & $<0.001$ & $214(44.4)$ & $7,983(24.9)$ & $<0.001$ \\
\hline Acute myocardial infarction & $53(11.8)$ & $137(3.3)$ & $<0.001$ & $74(15.4)$ & $2,473(7.7)$ & $<0.001$ \\
\hline Heart failure or acute myocardial infarction & $194(44.0)$ & $585(14.2)$ & $<0.001$ & $241(50.0)$ & $9,241(28.8)$ & $<0.001$ \\
\hline Diabetes & $203(46.0)$ & $385(9.3)$ & $<0.001$ & $314(65.2)$ & 6,697 (20.9) & $<0.001$ \\
\hline Chronic kidney disease/renal failure & $111(25.2)$ & $173(4.2)$ & $<0.001$ & $151(31.3)$ & $3,455(10.8)$ & $<0.001$ \\
\hline Cerebrovascular disease & $39(8.8)$ & $165(4.0)$ & $<0.001$ & $83(17.2)$ & $4,653(14.5)$ & 0.095 \\
\hline Chronic obstructive pulmonary disease & $23(5.2)$ & $79(1.9)$ & $<0.001$ & $60(12.5)$ & $2,920(9.1)$ & 0.012 \\
\hline History of smoking & $271(61.5)$ & $1,743(42.2)$ & $<0.001$ & $261(54.2)$ & $14,335(44.7)$ & $<0.001$ \\
\hline History of alcohol-related admissions & $211(47.9)$ & $345(8.4)$ & $<0.001$ & $121(25.1)$ & $1,317(4.1)$ & $<0.001$ \\
\hline \multicolumn{7}{|l|}{ Charlson Comorbidity Index, n (\%) } \\
\hline 0 & $96(21.8)$ & $2,613(63.3)$ & \multirow{4}{*}{$<0.001$} & $46(9.5)$ & $9.392(29.3)$ & \multirow{4}{*}{$<0.001$} \\
\hline $1-2$ & $156(35.4)$ & $1,054(25.5)$ & & $142(29.5)$ & $11,643(36.3)$ & \\
\hline $3-4$ & 80 (18.1) & 234 (5.7) & & $113(23.4)$ & 5,869 (18.3) & \\
\hline$>4$ & 109 (24.7) & $228(5.5)$ & & $181(37.6)$ & $5,141(16.0)$ & \\
\hline
\end{tabular}

p-value is for difference between Aboriginal and non-Aboriginal patients

* Patients could have multiple comorbidities.

$\dagger$ All ischaemic heart disease includes acute myocardial infarction. 
Table 3: Distribution of $\mathrm{CHA}_{2} \mathrm{DS}_{2}$-VASc scores* in non-rheumatic hospitalised patients with atrial fibrillation, by age group and Aboriginal status, Western Australia 2000-09

\begin{tabular}{|c|c|c|c|c|c|c|c|c|}
\hline \multirow[b]{2}{*}{$\begin{array}{l}\mathrm{CHA}_{2} \mathrm{DS}_{2} \mathrm{VASc} \\
\text { Score }\end{array}$} & \multicolumn{2}{|c|}{ 20-54 years } & \multicolumn{2}{|c|}{ 55-64 years } & \multicolumn{2}{|c|}{$65-74$ years } & \multicolumn{2}{|c|}{ 75-84 years } \\
\hline & $\begin{array}{l}\text { Aboriginal } \\
\mathrm{n}(\%)\end{array}$ & $\begin{array}{l}\text { Non- } \\
\text { Aboriginal } \\
\mathrm{n}(\%)\end{array}$ & $\begin{array}{l}\text { Aboriginal } \\
\mathrm{n}(\%)\end{array}$ & $\begin{array}{l}\text { Non- } \\
\text { Aboriginal } \\
\mathrm{n}(\%)\end{array}$ & $\begin{array}{l}\text { Aboriginal } \\
\mathrm{n}(\%)\end{array}$ & $\begin{array}{l}\text { Non- } \\
\text { Aboriginal } \\
\text { n (\%) }\end{array}$ & Aboriginal n (\%) & $\begin{array}{l}\text { Non- } \\
\text { Aboriginal } \\
\text { n (\%) }\end{array}$ \\
\hline 0 & $78(20.6)$ & $2,229(55.0)$ & $26(10.8)$ & $2,204(36.4)$ & 0 & 0 & 0 & 0 \\
\hline 1 & $102(26.9)$ & $1,257(31.0)$ & $40(16.7)$ & $2,172(35.9)$ & $15(9.8)$ & 2,819 (26.2) & 0 & 0 \\
\hline $2-3$ & 147 (38.8) & 523 (12.9) & $116(48.3)$ & $1,486(24.5)$ & 59 (38.6) & 6,009 (55.8) & 18 (25.7) & $6,842(46.7)$ \\
\hline $4-5$ & $52(13.7)$ & $42(1.1)$ & $58(24.2)$ & $191(3.2)$ & $69(45.1)$ & 1,808 (16.8) & $34(48.6)$ & $6,474(44.2)$ \\
\hline $6+$ & 0 & 0 & 0 & 0 & $10(6.5)$ & $134(1.2)$ & $18(25.7)$ & $1,337(9.1)$ \\
\hline
\end{tabular}

The global chi-square test ( $4 \mathrm{df}$ ) comparing $\mathrm{CHA}_{2} \mathrm{DS}_{2}$-VASc score for Aboriginal and Non-Aboriginal patients was significant ( $\mathrm{p}<0.001$ ) for every age group.

*Variables included in score based on administrative data: history of heart failure, hypertension, age (65-74 years=1 point; 75+ years=2 points), diabetes, cerebrovascular disease, vascular disease, sex (female=1 point) 
Table 4: $\quad$ Aboriginal to non-Aboriginal ratios from multivariate regression models* for 30-day mortality (odds ratios) and 1-year mortality in 30-day survivors (hazard ratios) following first-ever hospitalisation for atrial fibrillation

\begin{tabular}{|c|c|c|c|c|c|c|c|c|c|}
\hline & \multirow{2}{*}{\multicolumn{3}{|c|}{ 30-day mortality (events=2,588) }} & \multirow{2}{*}{\multicolumn{3}{|c|}{$\begin{array}{c}\text { 1-year mortality (events }=3,058) \\
\text { 30-day survivors }\end{array}$}} & \multirow{2}{*}{\multicolumn{3}{|c|}{$\begin{array}{c}\text { 1-year mortality (events }=5,417) \\
\text { Whole cohort }\end{array}$}} \\
\hline & & & & & & & & & \\
\hline & \multicolumn{2}{|c|}{ Odds Ratio (95\% CI) } & p-value & \multicolumn{2}{|c|}{ Hazard Ratio (95\% CI) } & \multirow[t]{2}{*}{ p-value } & \multicolumn{2}{|c|}{ Hazard Ratio (95\% CI) } & \multirow[t]{2}{*}{ p-value } \\
\hline Progressive Adjustment & & & & & & & & & \\
\hline crude & 1.00 & $(0.77-1.29)$ & 0.991 & 1.50 & $(1.24-1.82)$ & $<0.001$ & 1.28 & $(1.09-1.49)$ & 0.002 \\
\hline age & 1.75 & $(1.34-2.28)$ & $<0.001$ & 3.04 & $(2.5-3.7)$ & $<0.001$ & 2.40 & $(2.05-2.81)$ & $<0.001$ \\
\hline Demographics & 1.65 & $(1.23-2.19)$ & 0.001 & 2.94 & $(2.36-3.67)$ & $<0.001$ & 2.32 & $(1.94-2.76)$ & $<0.001$ \\
\hline Principal/secondary AF diagnosis & 1.10 & $(0.82-1.46)$ & 0.54 & 2.33 & $(1.86-2.91)$ & $<0.001$ & 1.73 & $(1.45-2.06)$ & $<0.001$ \\
\hline Comorbidities** (full model) & 0.81 & $(0.59-1.01)$ & 0.186 & 1.58 & $(1.26-1.99)$ & $<0.001$ & 1.24 & $(1.03-1.48)$ & 0.022 \\
\hline \multicolumn{10}{|l|}{ Stratified } \\
\hline All age, both sexes (full model) & 0.81 & $(0.59-1.01)$ & 0.186 & 1.58 & $(1.26-1.99)$ & $<0.001$ & 1.24 & $(1.03-1.48)$ & 0.022 \\
\hline$<55$ years, both sexes & 0.87 & $(0.45-1.69)$ & 0.672 & 1.21 & $(0.68-2.17)$ & 0.514 & 0.98 & $(0.63-1.51)$ & 0.929 \\
\hline All ages, males & 0.70 & $(0.45-1.08)$ & 0.111 & 1.42 & $(1.03-1.96)$ & 0.033 & 1.11 & $(0.86-1.43)$ & 0.432 \\
\hline All ages, females & 0.95 & $(0.61-1.48)$ & 0.832 & 1.72 & $(1.23-2.41)$ & 0.001 & 1.33 & $(1.02-1.72)$ & 0.033 \\
\hline \multicolumn{10}{|c|}{ Varying definitions of Aboriginal status } \\
\hline Aboriginal on $>=25 \%$ of admissions & 0.81 & $(0.59-1.01)$ & 0.186 & 1.58 & $(1.26-1.99)$ & $<0.001$ & 1.24 & $(1.03-1.48)$ & 0.022 \\
\hline Ever identified as Aboriginal & 0.80 & $(0.61-1.05)$ & 0.111 & 1.53 & $(1.26-1.86)$ & $<0.001$ & 1.22 & $(1.05-1.43)$ & 0.012 \\
\hline Aboriginal on Index admission & 0.79 & $(0.58-1.08)$ & 0.145 & 1.62 & $(1.24-1.96)$ & $<0.001$ & 1.23 & $(1.02-1.48)$ & 0.026 \\
\hline
\end{tabular}

\footnotetext{
*Logistic regression was used for 30-day mortality and Cox regression for 1-year mortality.

30-day mortality for index events January 2000 to November 2009, allowing for 30 days follow-up

1-year mortality for index events January 2000 to Dec 2008, allowing for 1 year follow-up

** Comorbidities include history of or current IHD, rheumatic/valvular heart disease, alcohol-related admissions, heart failure, diabetes, chronic kidney disease, chronic obstructive pulmonary disease, stroke, hypertension/hypertensive heart disease plus Charlson comorbidity index
} 


\section{References}

1.Alonso A, Bengtson LGS. A rising tide: The global epidemic of Atrial Fibrillation. Circulation. 2014;129:829-30.

2.Ball J, Carrington MJ, McMurray JJV, et al. Atrial Fibrillation: Profile and burden of an evolving epidemic in the 21st Century. International Journal of Cardiology. 2013;167:180724.

3.Chugh SS, Havmoeller R, Narayanan K, et al. Worldwide epidemiology of atrial fibrillation: a Global Burden of Disease 2010 Study. Circulation. 2013;129(8):837-47. 4.Lip GYH, Brechin CM, Lane DA. The Global burden of atrial fibrillation and stroke: a systematic review of the epidemiology of atrial fibrillation in regions outside North America and Europe. CHEST 2012;142(6):1489-98.

5.Benjamin EJ, D’Agostino RB, Silbershatz H, et al. Impact of Atrial Fibrillation on the Risk of Death: The Framingham Heart Study. Circulation. 1998;98:946-52.

6.Rienstra M, Lyass A, Murabito JM, et al. Reciprocal relations between physical disability, subjective health and atrial fibrillation: the Framingham Heart Study. Am Heart J. 2013;166:171-8.

7.Anand SS, Yusuf S, Jacobs R, et al. Risk factors, atherosclerosis, and cardiovascular disease among Aboriginal people in Canada: the Study of Health Assessment and Risk Evaluation in Aboriginal Peoples (SHARE-AP). Lancet 2001;358(9288):1147-53.

8.Atzema CL, Kapral M, Klein-Geltink J, et al. Cardiovascular disease in the Metis Nation on Ontario: technical report. Ottawa: Institute for Clinical Evaluative Sciences, 2012.

9.Howard BV, Lee ET, Cowan LD, et al. Rising Tide of Cardiovascular Disease in American Indians: The Strong Heart Study. Circulation. 1999;99:2389-95.

10.Vos T, Barker B, Begg S, et al. Burden of disease and injury in Aboriginal and Torres Strait Islander Peoples: the Indigenous health gap. Int J Epidemiol. 2009;38(2):470-7. 
11.Australian Bureau of Statistics. Life Tables for Aboriginal and Torres Strait Islander Australian, 2010-2012. Canberra: ABS, 2013 Release No 3238.0.55.001.

12.Australian Bureau of Statistics. Estimates of Aboriginal and Torres Strait Islander Australians, June 2011 Canberra: ABS, 2013 Release no 3238.0.55.001

13.Hanna JN, Heazlewood RJ. The epidemiology of acute rheumatic fever in Indigenous people in north Queensland. Aust N Z J Public Health 2005;29:313-7.

14.Katzenellenbogen JM, Sanfilippo FM, Hobbs MST, et al. Incidence of and case fatality following acute myocardial infarction in Aboriginal and non-Aboriginal Western Australians (2000-2004): a linked data study. Heart, Lung \& Circulation. 2010;19:717-25.

15.Randall DA, Jorm LR, S. L, et al. Exploring disparities in acute myocardial infarction events between Aboriginal and non-Aboriginal Australians:Roles of age, gender, geography and area-level disadvantage. Health \& Place 2014;28:58-66.

16.Teng TK, Katzenellenbogen JM, Thompson SC, et al. Incidence of first heart failure hospitalization and mortality in Aboriginal and non-Aboriginal patients in Western Australia, 2000-2009. International Journal of Cardiology 2014;173(1):110-7.

17.Katzenellenbogen JM, Vos T, Somerford P, et al. Burden of Stroke in Indigenous Western Australians A Study Using Data Linkage. Stroke. 2011;42:1515-21.

18.Holman CD, Bass AJ, Rouse IL, et al. Population-based linkage of health records in Western Australia: development of a health services research linked database. Australian \& New Zealand Journal of Public Health. 1999;23(5):453-9.

19.Jover E, Rolda V, Gallego P, et al. Predictive Value of the CHA2DS2-VASc Score in Atrial Fibrillation Patients at High Risk for Stroke Despite Oral Anticoagulation. Rev Esp Cardiol. 2012;65(7):627-33. 
20.Australian Institute of Health and Welfare. Rural, regional and remote health: a guide to remoteness classification. Canberra2004. Available from:

http://www.aihw.gov.au/publication-detail/?id=6442467589.

21.Australian Bureau of Statistics. Information paper: census of population and housing socio-economic indexes for areas, Australia. Canberra2003. Available from:

http://www.ausstats.abs.gov.au/ausstats/free.nsf/0/AFF5E8542B58B94ECA256DD5007A3D F8/\$File/20390_2001.pdf.

22. Thompson SC, Woods JA, Katzenellenbogen JM. The quality of Indigenous identification in administrative health data in Australia: insights from studies using data linkage. BMC Medical Informatics and Decision Making 2012;12(133):doi:10.1186/472-6947-12-133

23.Australian Bureau of Statistics. Australian Aboriginal and Torres Strait Islander Health Survey 2012-13. Canberra: ABS, 2014.

24.Brown A, Carrington MJ, McGrady M, et al. Cardiometabolic risk and disease in Indigenous Australians: The heart of the heart study. Int J Cardiol. 2014;171:377-83. 25.Brown AD, Morrissey MJ, Sherwood JM, et al. Uncovering the determinants of cardiovascular disease among Indigenous people. Ethnicity \& Health. 2006;11(2):191-210. 26.Wong CX, Brooks AG, Cheng YH, et al. Atrial fibrillation in Indigenous and nonIndigenous Australians: a cross-sectional study. BMJ Open. 2014;4(10):e006242. 27.Borzecki AM, Bridgers DK, Liebschutz JM, et al. Racial differences in the prevalence of atrial fibrillation among males. J Natl Med Assoc. 2008;100(2):237-45.

28.Robson B, Robson C, Harris R, et al. Hauora: Māori Standards of Health IV. Wellington: University of Otago, 2007.

29.Bersh B, Freedman JE, Granger CB. Antiplatelet and anticoagulant therapy for stroke prevention in patients with non-valvular atrial fibrillation: evidence based strategies and new developments. Rev Esp Cardiol. 2011;64(4):260-8. 
30.Jensen PN, Johnson K, Floyd J, et al. Identifying atrial fibrillation from electronic medical data: a systematic review. Pharmacoepidemiol Drug Saf. 2012;21(01):141-7. 